\title{
i.
}

\section{ATOMLLL-A THREE-D OPAQUE MOLECULE SYSTEM (LAWRENCE LIVERMORE LABORATORY VERSION)}

N. L. Max

January 11. 1979

Work performed under the auspices of the U.S Department of

Energy by the UCLLL under contract number W-7405-ENG-48.

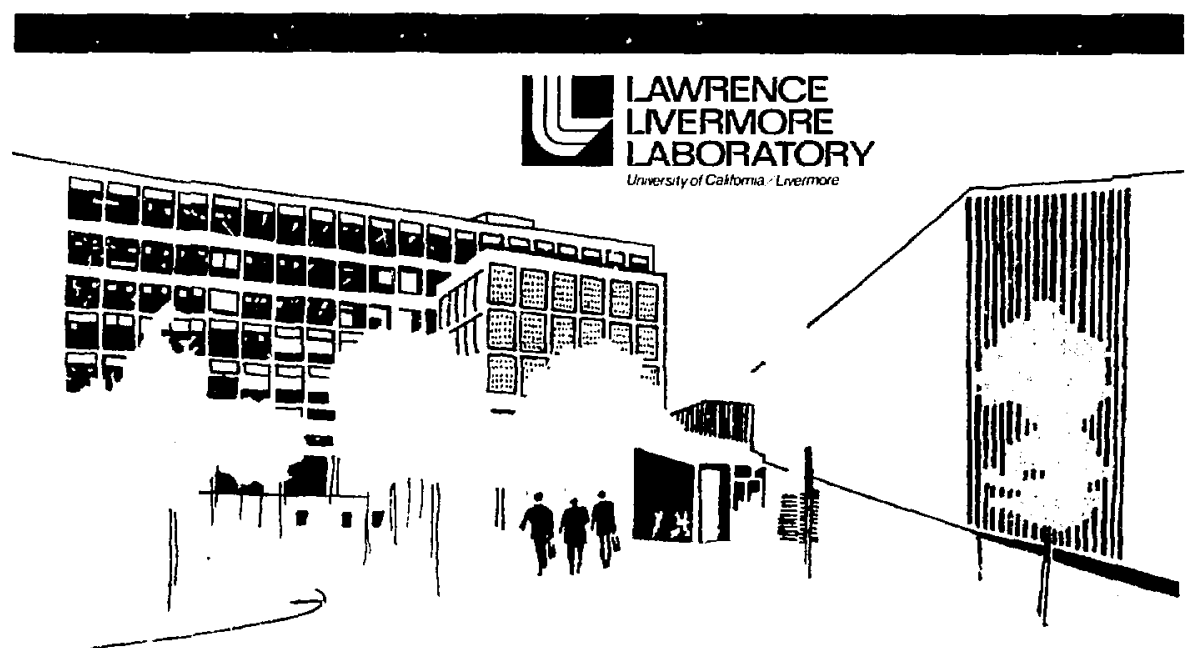




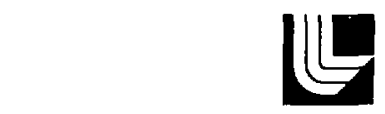

\title{
I_AWRENCE LIVERMORE I_ABORATORY
}

University ot Caltorna Livermore California 94550

\section{ATOMLLL-A THREE-D OPAQUE MOLECLLE SYSTEM (LAWRENCE LIVERMORE LABORATORY VERSION)}

\author{
N. 1.. Mik
}

Manuscript datc: January 11. 1979)

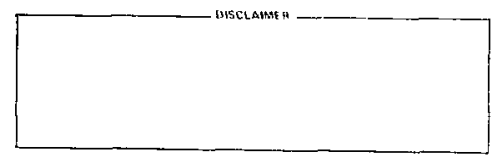




\section{AVAILABILITY}

This document is avallable online as follows:

XPORT RD .717675:LCRL::LCRI.52645/11

RD .717675: LOCRL:LX52645

View the file on the TMDS using the TRIX AC command:

TVnn $, 1,8,85 ! \mathrm{N} ! \mathrm{T}$

To print the file, type:

$\operatorname{TRIXAC/11}$

.PRIXT!NIP LCRL.52645 BOX anr identificalion . END

To $\because \mathrm{icw}$ thls file on the TMlls with fult font capabilitios and pietures, Use REDPP as deseribed in UCID-30125. To print the file with fult lont capabilities and piclures, use the REDPP exceution line:

REDPP filenane NIPS. / 22.2

Remember, the TRIX AC comands use far less computer time than the REDPP command. 


\section{CONTENTS}

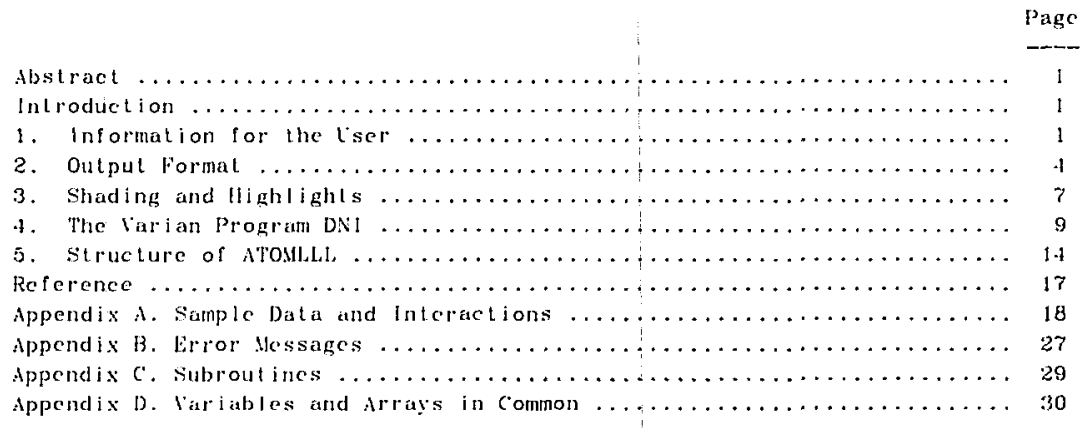




\title{
ATOMLLL-A THREE-D OPAQUE MOLECULE SYSTEM (LAWRENCE LIVERMORE LABORATORY VERSION)
}

\begin{abstract}
The program Alowhl, draws color, shaded, hidden-surface pictures and movies of "ball-ind-slick" and "space-filling" moleeular models. From a lile contalutur the colors and radi of the atoms, the coordinates of their centers. and libe deserpetions of bonds, if any, the program compules the visible portions

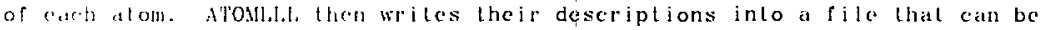
copic to lape. The lape is read by a larian minicomputer. which controls the plot ills on the Dicomed D-48 color-film recorder.
\end{abstract}

\section{INTRODUCTION}

$\therefore$ He H Hu (lawlence Livermore haboralory Computer Graphics Group)

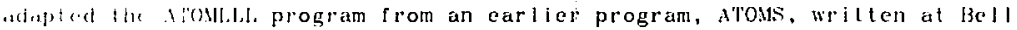
i.whoralarles bs ken Knowlton and Lorinda Chelry. 1 added the information for Fhatme and highlights to the output and wrole the program to produce the shadine sh the Dicomed. Bell telephone Laboralories and Lawrenee Livermore lateralor: lake no responsibility for maintaining exported eopies of the codes

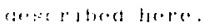

The for set setion gives the teletype interaction and input dalia format. b. sertion. lhe sample data and interactions in Appendix $A$, and lhe list of

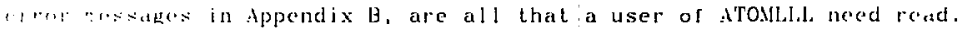
$\therefore$ list : discusses output data formal; section 3 outlines the strutegy of the

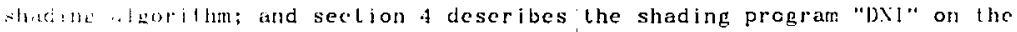
..1 ..th. These threc sections will be of use to those who wish to plol the out int on other devices. Finally, section 5 partially describes the strueture of the subroulines in Atoml.l., and Appendix $C$ lists its common blocks and barablas. This information may be of help to those who wish lo adiat the prosram to other installations; possible modifications are mentioned.

\section{INFORMATION FOR THE USER}

The source progran ATOMLIJ, and the load module ATOMC are atai able in the diroctory .020!25:GGlBLIC. When you start ATOMC, it will ask

OL'TINAS ON TMDS? F or $N$

If you lype i' you will be asked 
In this mode, the outlines of the visible portions of each alom or bond in the piclure will appear on the monitor in addition to the more complete descriplion in the oulput file. This feature can be used to debug a piclure or movie filc. The syslem will prinl

$>$

when a new frame is ready and hold the current frame on the screen until a calviage return is supplied.

The next prompt is

INPUT' F ILE NAME:

which should be answered by the name, up to 10 characters. of the input file. Finally the program asks for the

OUTPUT FILE NAME :

which can hasc up lo 9 characters.

The program requests 670,00060 -bit words on disk for the oulpul file. When the current file is filled, ATowLL aulomalically increments the name by one (changing the last character to the following letler or number) and opens a new file. The program reports each new lile crealed lo the lerminal. The files can be copied to tape by TAPECOPY. Each Lakes aboul one-third of a 2200-rt reel of $B 00-\mathrm{bpi}$ lape.

Carry the lapes to the rack outside the Dicomed room and attach a white instruclion slip, with your box number, for film delivery. Request the lape to be ruI by DNI (sec section 4). If you want the results to be mountable as ruli-frame $35 \mathrm{~mm}$ slides, request [FDA=l. This will nol increase the image size, but will have unexposed black film fill the frame of the $B$ perforated slide mourts. The same lape may be plolled al 1024, 2048, or 4096 pixels resolution. The higher resolutions give cleaner edges, bul lake longer to plol. Generally, 2048 is good enough for movies. The 4096 resolution should be used only for 4by 5 -in. sheet $1 \mathrm{ilm}$.

The picture is clipped in the CDC 7600 computer to height of 0.75 limes its widh. Which is the aspect ratio of movie film. Thus parts of the picture hidden by the camera aperture plate will not be drawn. If you want the full square frame [which can only be plotled on Polaroid sheet film or on the Lelovision monitor display system (TMDS) screen], you must change the line ARATIO=.75 in the subroutine SETDAT to specify the desired aspecl ratio (1.0 for a square).

The input flle lists the information necessary to describe each frame of the movje. The first line for each frame lists the numbers, NatoMs, of atoms for the frame, and the perspective ratio PRATIO. These are given in the cormat 
16. F6.2. (Note that the 2 in $F 6.2$ is only a defialt if the input has no decimal point. Any decimal point in the 8-character input field takes priorily.) The number PRATIO is the ratio of screen width to viewer's distance from the sereen. A value of PRATIO belween 0.3 and 0.5 gives a reasonably comfortable perspective.

The next NATOMS lines give the $X, Y$, and $Z$ coordinates of each atom, the radius of the sphere used to represent $i l$, and the color of that sphere in the formal AF6.2, 13, The color is an integer from 1 to 7 , corresponding to the seven colors on the Dicomed tilter whel, in this order: red, green, yellow, blue, magenta, cyan, and white. If two spheres interpenetrate, their intersection will be computed, and only the visible portions rendered. By choosing radi near the van der liaals radi of the atoms, a realistic simulation of the plastic "CPK space-filling models" is produced. The viewpoint is assumed lo be at the origin, so all atoms must have positive $z$ coordinales to be visible.

If smaller radi i are used, so there is space belween aloms, covalent bonds can be represented by cylinders or "sticks" connecting atomic centers. This results in ball-and-stick models. Again, although the sticks intersect the spheres, only the visible portions are rendered. However, the sphercs must be large cnough to cover any potential intersections of sticks, since the program will nol correctly render such intersections. In this report, the word "part" refers cither to a sphere representing an atom or to a cylinder representing a bond. Parts are numbered by the order in which they appear in the input file, with the first bond following the last atom.

The next line of the input file contains the number. NBONDS, of these sticks and their default radius, BONDI, in the format 16, F6.2. If there are no bonds, this line must still be given, with NBONDS=0. If BONDR=0, the radi of the various bonds are laken from the succeeding lines.

The next NBONDS lines contain the part numbers of the two atoms connceted by each bond, and the radius of the bond, in the formal 213, F6.2. The current color for all bonds is magenla bul can be modified by changing the Varian program DNI. If BONDR is nonzero, il takes priority, and the radij need not be listed on each ine.

Afler the bond description, the line with NATOMS and PRATIO may be entered for the next frame, and the process repeated. Successive frames of a movie are thus concalenated in the input file. When the progran sees the end of file after the last frame: (1) an end-of-job indicalor is written on the output; (2) the outpul buffer is eleared to disk; (3) the number of 660 -word records written $t$, the last oulput file is reported on the terminalif and (4) the program exils, typing ALL DONE. 


\section{OUTPUT FORMAT}

As described in Ref. i, ATOMLLL keeps track of the visible portions of each parl in terms of a list of "trapezoids." Each trapezoid (Fig. 1) has two straighl vertical sides.

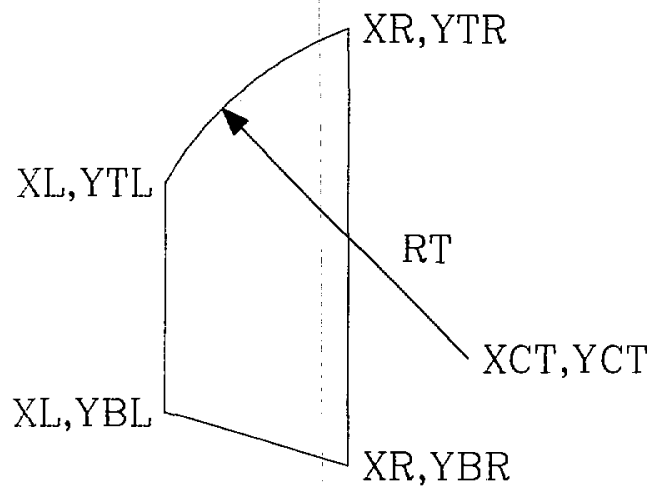

Fig. 1. A trapezoid, whose top arc is concave downward and whose bottom arc is a straight line.

The other two sides may be straight lines, or arcs of circles, and the lerm "arc" will refer to either of these. The circular ares can be convex down, as the top arc in Fig. 1, or convex up. In addition, each arc must be monotone, with $Y$ either nonincreasing or nondecreasing. Thus, a sphere is initially represenled as two trapezoids, each having one degenerate vertical side (Fig. 2(a)). Occlusions or intersections of this sphere with other spheres or cylinders will result in subdividing, reducing, or removing some trapezoids in this list (Figs. $2(b)$ and $2(c)$ ), and perhaps joining adjacent ones (Fig. $2(d)$ ). 


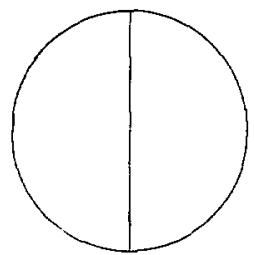

Fig. 2.(a) Inilial subdivision of an atom.

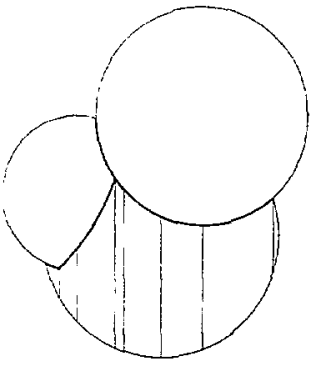

Fig. 2. (c) Further subdivision caused by oceluding atom.

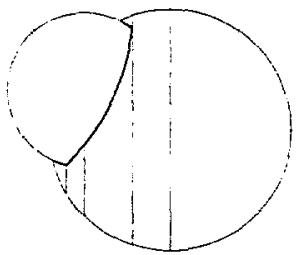

Pig 2.(b) Subdivision caused by intersecting atom.

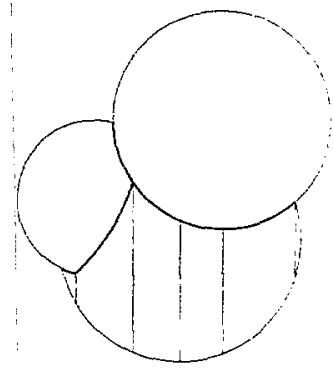

Fig.:2.(d) Subdivision after COMPACT has joined adjacent trapezoids.

After all potential occlusions have been taken inlo accounl, the final list of trapezoids for each part is writlen te the output file.

It takes 11 numbers to describe each Lrapezoid, arranged on output as a row in the $200 \times 11$ matrix KOUT. Inside ATOMLLL and DNI, they are called J, KT, KB, $X L, X R, X C I, Y C I, R T, X C B, Y C B$, and $R B$. The first three are integers: $J$ is the atom or bond number from which the trapezoid comes (used only for debugging) and K't and KB describe the type of the upper and lower arcs, 1 for convex downward, 2 for convex upward, and $?$ for straight. The next eight are real numbers: XL and $X R$ are the X-coordinates of the left and righl verlical sides (Fig. 1): XCT, $Y C T$, and fir aro the center and radius of the upper arc; and XCB, YCB, and RB are 
the conter and radius of the lower arc. The screen is assumed to have boundaries at $X=-1, X=1, Y=-A R A T 10$, and $Y=$ ARATIO. The program ATOMLLL also keeps track of YTL, YBL, YTR, and YBR (the Y-coordinates of the corners) as an aid in processing the trapezoid 1 ist: but these are not needed in the output.

Since it is easier and quicker for the Varian to read fixed point binary data, all real coordinates and radij are multiplied by $2^{14}$ and converted to integers for outpul. This "normalizalion" allows a range from -2 to 2 for these real numbers, and the resulting integers become sereen ccordinates lor the bicomed.

Circular arcs of small curvature, requiring centers or radii oulside this range, are converted to straight lines on cutput. In addition, lines of slope greater than 1 or less than -1 are represented by their reciprocal slopes and $x$-intercepls, again lo keep the numbers in range. This gives a new class of are, lype 4, used only in the outpul.

If the bottom are is of lype 3 , as in Fig. 1, the ninth number, XCB, will bc $\left[\left(2^{15}\right)-1\right]$ times its slope; the tenth number. YCB, will be meaningless; and the last, RB, will be the normalized Y-intercept. Similariz, if it is of type 4 , XCB indicates the reciprocal of the slope and $R B$ indicaics the $X$-intercept. The corresponding interpretalions hold for the top are. (This applies only to the outpul file. Internally, in ATOMLLL, these are reversed: $R$ denoles the slope and $\mathrm{XC}$ denoles the $\mathrm{Y}$-intercepl.)

A tape record contains 200 rows of the $200 \times 11$ matrix KOUT in columnise order by FORTRAN conversion. If the first entry, J, of a row is positive, a trapezoid is indicaied, arising $f$ :om part $\mathrm{J}$. A negative $\mathrm{J}$ indicates one of four other kinds of information. A $J$ of -5 tells the Varian that a frame has been compleled, and the f $\mathrm{j} l \mathrm{~m}$ is advanced iefore further plotting. A $\mathrm{J}$ of -4 indicates the end of the run, and the job is lerninaled.

A $J$ of -3 indicates the beginning of a new sphere, and other entries in the row give data necessary to compute its shading. Specificaliy, the second entry is the color, the next two entries are the normalized $X$ anc; coordinates of the center, and the fifth entry is the normalized radius.

Finally, a $\mathrm{J}$ of -2 indicates the beginning of a cylinder for a bond. The shading algorithm needs to know the top edge, bottom edge, and center line of the cylinder; these are given in tiree groups of three numbers. In each group, the first number indicales tha hind of line. Ii it is 1 , the next number is [( $\left.\left.2^{15}\right)-1\right]$ times the slope, and what lollows is the normalized Y-intercept. If the first number is 2 , the reciprocal slope and $X$-intercept are used instead. The eleventh entry gives the hishl.ght intensity of the bond. which depends on the anglo between the axis of the cylinder and the light source. It is maximum, at $\left(2^{15}\right)-1$, when the bond is parallel to the picture plane.

As a ball-and-slick model rolates, bond highlighis flash on and of appropriately. Simultaneously, atom highlights turn correctly, remaining at the centers of the projected spheres. 


\section{SHADING AND HIGHLIGHTS}

Atoms are shaded as if they diffusely reflect the illumitral ing ligh!, which is assumed lo comp from an infinilely dislant point directly behind the viewer. Thus intensity is a monolone-decreasing function, $f(0)$, of the angle 0 belween the norma! $P N$ to a point $P$ on the spherc and the 7 axis (Fig. 3). A suitable runclion mighl be "Lamber!'s Iaw":

$$
f(\theta)=A+D \cos \theta
$$

where $D$ represents the diffuse reflectivity of the illuminating light from the surface and $A$ represents reflection of ambient light coming from all directions, so the sphere does not become totally black al the edges.

This function, $f(\theta)$, could be used to mulliply the three color components (red, grcen, blue) for any sphere. In the current version, onc of ile seven colored fillers is used, taking one pass to shade each sphcre instcad of three passes. However, the plotting program could be motified to usc three passes if more than seven colors were required. In this case, the sccond pass now usad to add the high! ights could be eliminaled.

The highlights represent specular reflection from the surfaces of the sphercs and cylinders and are added in while, with a sepurate pass through the cleir filter. Here, a function that concentrates the intensity a' small andes of $\theta$ is appropriate, for example,

$$
\mathrm{g}(\theta)=C \cos ^{28} \theta \text {. }
$$

(This particular expression gave an unpleasant Mach band around the centra) highlight, so several other lerms were added in the curreat implemenlation.)

The Dicomed contains a loadable color-lookup lable, designed to compensale for conlinearities in the output scope and the $\mathrm{film}$. Which takes an $8-b i t$ input intensity and gives an 8-bil oulput intensity to the scope. (Actually. the plotting intensily is kept constant, and the output of the lable controls the plotling time instead.) After a record of $200 \times 11$ words is read from tape, the shading function, $f(\theta)$, is entered into the table and the listed lrapezoids are shaded in their appropriale colors. Then $g(\theta)$ is entered and the highlights are added through the clear filter.

The functions $f$ and $g$ are actually tabulated in tcrms of $\cos ^{2} \theta$. I now demonstrale how $\cos \theta$ can be eificiently compuled along a vertical scan line, using finite differences. 


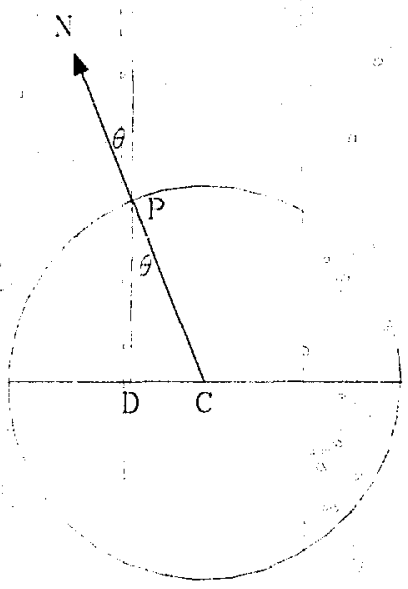

Fig. 3. Section of a sphere normal to the viewing plane, showing angle of incidence, $\theta$, belween illuminating ray and normal veclor, PN.

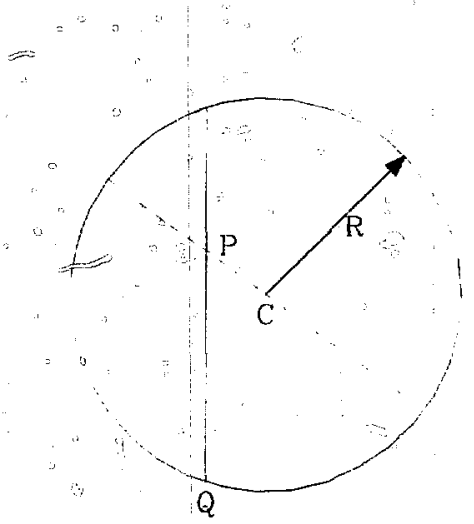

Fig. 4, Projection of sphere on a viewing plane. The dotled line is the projection of the plane of Fig. 3.

Figure 4 shows the projection of a sphere onto the picture plane. The point $P=(X, Y, Z)$ is on the sphere's surface, $C=(X C, Y C, Z C)$ is the center, and $R$ is the radius. Figure 3 shows a section of this sphere, in a plane perpendicular to the dotted line.

From triangle PDC in Fig. 3 , one finds

$$
\cos ^{2} \theta=\frac{\overline{\mathrm{PD}}^{2}}{\overline{\mathrm{PC}}^{2}}=\frac{(\mathrm{Z}-\mathrm{ZC})^{2}}{\mathrm{R}^{2}}
$$

Solving the equation of the sphere,

$$
(X-X C)^{2}+(Y-Y C)^{2}+(Z-Z C)^{2}=R^{2} .
$$

for $(2-2 C)^{2}$; and substituting in Eq. (3), I get

$$
\cos ^{2} \theta=\frac{R^{2}-(X-X C)^{2}-(Y-Y C)^{2}}{R^{2}} .
$$


Since the trapezoids have vertical sides, they are eolored in vertical raster-scan lines. Along a vertical line sueh as the one shown in $F$ ig. 4 , the quantities $R, X, X C$, and $Y C$ are eonstanl, so $F q$. (5) represents a quadratic polynomial in $Y$. Titis polynomial is evaluated at successive points along the scan line, using finite differences. The second difference for any quadralic polynomial is a constant, equal to its second derivative. Thus only two differcnces are required, and the value accumulaled from the differences will be exact.

\section{THE VARIAN PROGRAM DNI}

The Varian program DNI initializes the value kl of $\cos ^{2} \theta$ at the lowest point $Q$ of the scan line, its first difference K2, ils sccond differeace k3, and the number $N$ of points lo be plotled. Then successive values of $K l$ can be plotled by the FORTRAN loop

$$
\begin{aligned}
& \text { DO } 1 \quad I=1, N \\
& \text { PLO' }(k 1) \\
& k 1=k 1+k 2 \\
& 1 k 2=k 2+k 3 .
\end{aligned}
$$

Here. PLOT takes the higher order 8 bits of $K L$ and stores them in a buf ler. which is sent through the color-lookup table when full. Double buffering is used so the Dicomed can plot one buffer while the Varian fills another.

Since a vertical scan line may have $\mathrm{N}$ greater than 1000, and $\mathrm{Ka}$ is added effectively $\aleph^{2} / 2$ limes in determining the last $K 1$. double precision integer arithmetjc is required. Double-word integers on the Varian have a sign bit and go dala bits. (The sign bit in the lower order word is not used.)

If $\cos ^{2} 0$, which varies from 0 to 1 , is multiplied by $\left(2^{\theta}-1\right) \cdot 2^{22}$. the higher order 8 data bits $w i l l$ be in the appropriate range. Therefore. if $B=\left(2^{8}-1\right) \cdot 2^{22} / R^{2}$ and $X$ and $Y$ are the coordinates, for $Q$. one has

$$
K L=B *(R * 2-(X-X C) * 2-(Y-Y C) * 2) \text {. }
$$

The Dicomed is capable of coloring in an $n^{*}$ m raster rectangle for each byte in the dala buffer, and this feature is used for plotting at less than maximum resolution. Thus, if JSP is the number of raster positions skipped on each step through the loop, K2 can be found by evaluating Eq. (7) at $Y+J S P$ and subtracting the value at $Y$, giving

$$
K 2=-2 * B * j S P *(Y-Y C)-B * J S P * J S P \text {. }
$$

The first term corresponds to the derivative of Eq. (7) and the second can be interpreted as a correction to get a secant line instead of a tangent. An equation for K3 can be delermined similarly: 


$$
h i 3=-2 * 13 \cdot J S^{3} \cdot I S P
$$

These cquitions will nol aetually be found in the Varian program. since the constants like kis, which are intependent of the scan line, are compaled when the sphere is initialized rather than just before the loop. The current version does not contais loop (6) either. Because the machine instructions for double precision arithmelic are quite inefficient and a writeable control store was alaitable, the whole loop was replaced by a single new mierocoded instruction.

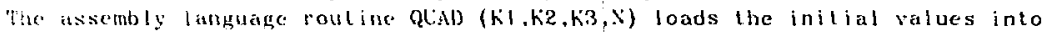
reglsters and calls this new instruction, which can execule the ivop in eight 195-n: microinstructions per iteration. For atoms that fill up a substantial areat of the sereen, the microcode can generate the tata fasler than the Dicomed ran plot 1t: but for smaller istoms, computing the upper and lower boundary ares of trapezoids becomes the bottleneck.

latilly, the shading for a cylinder is tlso a quadratic polynomial along a verlical scan line. Howevre, alter perspective projection, eylinders become conts and lac shading is no longer so simple, especially when the direetions of the projected codecs lic in different quadrants.

In Fig, $\bar{~}, Q A$ and $Q C$ aro the extentions of the projected edges of a bond and Ql3 is lhe projecled center line, all tneeting at the "vanishing point" $Q$.

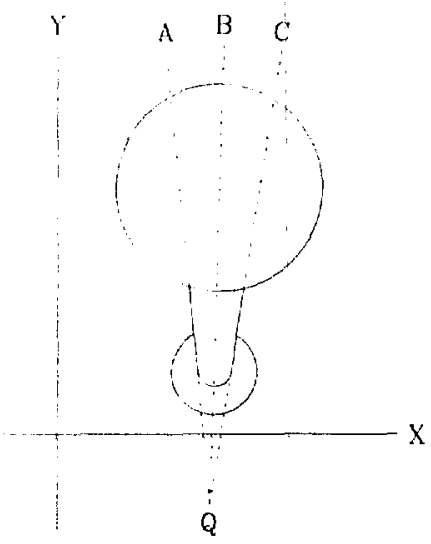

Pig. 5. Regions of piclure plane formed by exlended bond edges, $Q A$ and $Q C$, and centerline $Q B$; 
For litis cuse, the part of the bond lying $i n$ lQl will be shaded using quadratic polynomials on horizonlal scan lines. The part in BQC will be shaded using different polynomials on vertical scan lines. These polynomials are adjusted to have their maximum value (as specified by the eleventh ontry in the row initializing the bond) along the line QB and to be zero along QA and QC. Thus, they agree smoothly along $Q B$ and give a close approsimation to the true shading. In a movic, the assignment of sean directions may switch as a bend rotates. this may cause a slight change in the shading, but it is nol noticeable.

The following briefly describes the use and strueture of the DNl progratl. The MAN program starts by asking for two inlegers, WWIT and IDFA, in format 211. If IWAlT is l. the system pauses belween frames so sheel film ean be changed and continues when a carriage relutn is entered on the teletype. If :DFA is 1, a double advance is ealled belween frames to produce 35 mm pietures suitable for mount ing in full-frame slides. If one of these options is not wated. The operator should enter 0 ; if neither is wanted, the prompl can be answered with just a carriage relurn.

Next sliplal. is called, which reads a list of measured film densities from fhe rard reader and computes three sets of color-looiup tables: (1) for the color shading; (2) for the highlights; and (3) for the standard linear rompensation, replaced when the program exits. The desiled intensilies, Dt ror shading and be ior highlight:s. are computed in terms of t'k = costs. The Pormalas for D1 and De can be easily chatlged to give a different surface apperatance. To get the lookup lable output that will resull in a desired brighluess whet the film is vieved, the proglam inlerpolates between the blighlness resulting from the mrasured densities. (By definition, the density of film is the negative of the base 10 logarithm of the fraction of light the film transmils.)

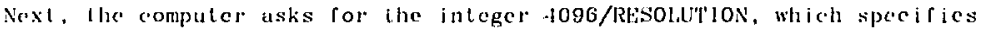
how latge a square pixe! should be plotled for each data byte. This number must be ather 1, ?, or 4 .

Each new lape is requested by the message

MOUN'I' NEW 'I'AIE' AND PRESS RE'T'URN

A record containing a $200 \times 11$ array of specifications is read as a block by the assembly langwage routine REED. Part-initializalion rows of the matrix are processed by MAIN, while TRAPEZF is called to shade the trapezoids, as deseribed above. Ihe parameter KIND is 1 if the trapezoid arises from an atom sphere and 2 if il arises rrom a bond eylinder.

Each time a part of a new color is encountered, NEwCol, is called to switch the color filter wheel and to specify a new minimum value, AP, and range, BP, of the color table input for that color. Color plotling terminales when either the end of the input arrays is reached $(I=201) \mathrm{or}$ an end-of-lrame indicator is encountered (NCI = -5). Then the clear filler is put in place, the color lable for the highlights is entered, and the same oulput dala is regenerated and sent lo the Dicomed to render the bighlights. The variable KSTAR' saves the index of 
the first data row for the next frame, which begins alter the highlights have been plotted and the film advaneed. The complete control flow to achieve all this is somewhal complex (as illustrated in the flowchart of Fig. 6).

If film is being recorded in three passes (red, green, and blue) for a greater varjely of atom colors, the tables should be reloaded for each atom color. Also, the three tables should inelude a component of white (equal parts of red, green, and bluc| near the center to give he hightight.

Similarly, if the oulput is being displayed on a frame buffer, a portion of the color table should be used to shade each colc and the white component for the highights should be included in the lable entries. 


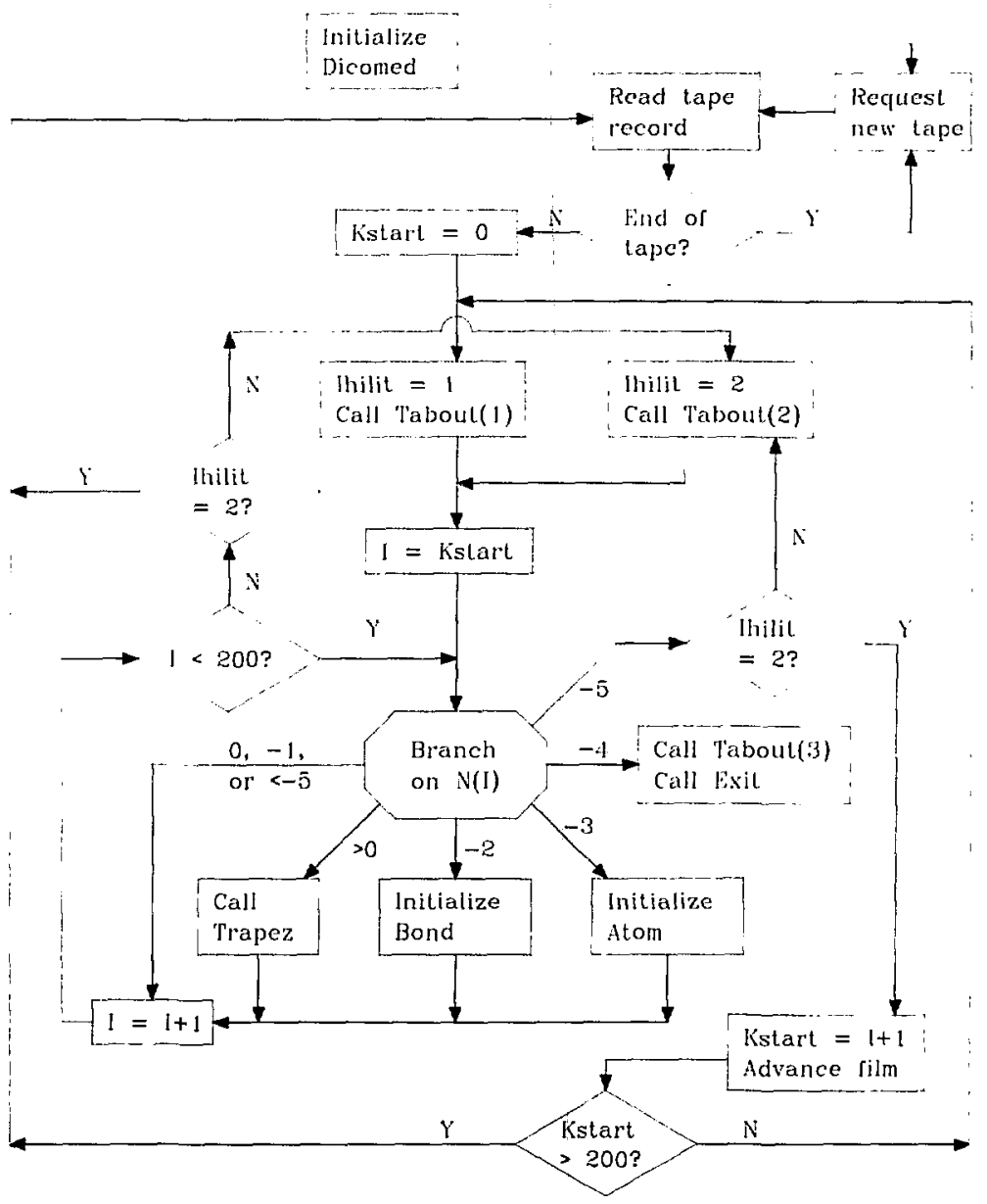

Fig. 6. Flowchart for section of a minicomputer program DNI that processes input buffer from tape. Each frame in the buffer has its atoms and bond trapezoids rendered (a) for shading, in color, and (b) for highlights, in white. 


\section{STRUCTURE OF ATOMLLL}

Appendix ( contains a table of subroutines in ATosl.t.l. This lable has a shorl phrase describing their runctions and shows their page number in the listing. Further information is available from the comments at the beginning of aach subrouline, from the variables identified in Appendix D, and from the partial descriplion below.

The ATOMS program has been considerably debugged and revised since the version reported in Ref. 1. The pseudo-code in Fig. 6 of Rel. 1 was a simplification of the actual code even al the time of writing, and some of the limilations 1 n Ref. I do not apply. In parlieular, bonds will overlap each other correclly in the pieture plane, conlrary lo slatement 4 in the first section of Ref. 1, although they still must not intersect in space. Also, the curved edges, where bonds intersect their atoms, are rendered more realistically than the method suggested by Fig. 3 of Ref. 1. The coordinate transformalions have been removed to conserve memory, but may casily be replaced.

Tlie MAL program gets the approprialc file names from the user and ope:s the input and outpul files. For each frame, it calls SETDAT to read the atonis coordinales and bond data from the input file, it calls INllt. lo initialize the data structurc, and it calls PlcruR to do everything else. Ir the variable lWR, currently set equal to 0 , is changed to 1 , a file named lfFxt of intromediate data will be created. 'IEXT' can be used for debugging purposes to trace the progerss of the calculations.

Subrouline SETDAT reads in the alomic coordinates fron the input file. l'sers who want to interact with their picture on the lMDS by changing the point of view or the coordinates of the atoms, might replaee SFrDAl by their own rout ine to define or transform coordinates.

The first dimensions of many of the data arrays, currently 0605, can be easily decreased to save space or increased to render more aloms and bonds. Simply replace all symbols 0605 in the program by an allernate number. which is at least as large as the total number of parts: NiTONS plus ABONDS.

The quantily DELTAR is the half-width of the black line between different atoms and bonds regions. Since the TMDS shows the outline of these regions, its piciturc will consist mostly of double lines if DELTAR is positive; a more plcasing picture will pesult if DELTAR is zero. However, a positive value is needed for colored photographs to prevent adjacent differently colored regions from bleeding together. A positive value is also useful to accentuate the outlines.

Subroutine INITL eliminates atoms and bonds that lie outside the picture plane and locates the circles where bonds intersect the atoms they join.

A linked list of potential picture-plane interactions is maintained in common arrays IHTERE, NEXT, and LAST. For each part B, LAST(B) points to the boginning of $B^{\prime} s$ I ist. If $L$ is an index on $B^{\prime} s$ list, lWhERE(L) gives the number 
F of this interacting part and NEST(t) points to the nest item on the list for part $B$. If $F$ is positive, part $F$ may hide part B. If $F$ is nedative, part (-F) may "Iruncetc" par! B; I.e., parts $(-F)$ and $B$ intersect in space and this inlersection may affect the way they hide cach other. These lists ale initialized to zeros at the beginning of INITl. As INITl, proesses bonds, their interactions with the aloms they join are added to the $1 \mathrm{ist}$.

The nest goulipe, Pleteles, proeesses the array of parls, one rolor at a time. For rach part J of the correct color' $\mathrm{CC}$. KSCA is called to add to the interaction list any succeding parts that might inleract with $\mathrm{J}$. At the same time. the reverse inleractions of J with any other parts 11 are also noted, so J may be skipped when kschl considers the interactions for li. This avoids almost hatf the comparisons and saves significant time in the catse of complex piclures. at the expense of a lot of memory. For smatler pielures, the size of lWhetes and MEXT, currently +700 , could be decreased. (Nole also the $1700^{\circ}$ s in the seventh and ninth cxecutable stalements of IXITL.) Allematively, at the cxpense of some extra computer lime, all three arrays could be climinated and kscax rombincd with Diciest to find the interactions as they are proecssed.

After the current version of kscas updates the interaction list lo include all inleractions with part d, the list is plocessed by Dld list of visible trapezoids fol part $J$, 'lhe first step is tone by ('Thal, which oulputs lhe shading information for a part and which creates its initial list of trapezoids: lwo for an atom and up to seven for a bond. The parameters for these traperoids are slored in the alrays in common block lRAPP, starling wilh index 8. Thon ror each part in the list of potential interactions for part J. a list of "mask" trapezoids is crealed using the fifst seven entries in these alrays. 'line two lists are compared, trapezoid by trapezoid. If a mask Irapezoid overlaps a part trapezoid the routines 'IRAP, ATRAP, and MLIS" are cialled to remove the part trape\%oid and replace it with lhe preces into which it is chopped (Figs. $2 b$ and $2 c$ ). If any such inleraction has oceured for " masking part. CuIPNCl' is called to rejoin trapezoids adjacent in the piclure and also in the I ist. This may happen if the reason for their separation has now become hidden (Fig. 2(d)).

The delails of the routines DIGEST', TRAP, ATRAP, and ALIST, which form the heart of the hidden-surface algorithm, are beyond the scope of this report.

'Jhe rouline OL'T'PU' lakes the final i ist of visible trapesoids for a part, loads the data for each into an integer array ko of length 11 , and modifies it into the output formal desclibed in section 2. It then calls Wiltilif to copy ko into the oulpul buffer, KOUT. The nonvertical sides of each trape\%oid are also drawn on the T'MDS, if requested.

The rouline WRTHuF is also called when frames are completed or when the job is compleled. In addition, when new parts are created by CTRAP, WR'tBuF is called to set up the proper Iow of KOU'l as described in section 2 . In this case, the jnformation is taken from array LO instead of ko. When a record has been filled and outpul to disk, the old array to is copied as the first row of Koul for the new record. lluus the varian minicomputer can regain the initialization of the part if is drawing afler the inpul buffer is overwrillen. 
The larian reads 7-track lape in a mode requiring three 6-bit lape frames lo fill up a 16-bit word; it disregards the two higher order bits of the 18 read In.

On the other hand, the 7600 writes 10 tape trames per 60-bit word, wasting nothing. 'Thus the $200 \times 11$ array kou'l of 18-bit bytes is equivalent to the 660 (jo-bil word array KEQU for outpul. Actually, Kl:QU is first block-copied to

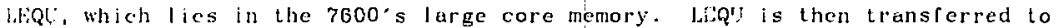
disk. I'his double lransfer speeds ap the 7600. since the second transfer can take place in parallel with other eompulations. On olher comput.rs, this will not be useful, so KEQU should be oulpul directly, and the firsl two lines after thr comments in WR'lBUF should be deleled.

Anolher quirk concerns the representalion of negative numbers. The 7600 is a two's-complement machine, with the possibility of negative zeros. However the output file must be read by the Varian, which is a one's-complement machine. Ther the stutement

$M O(M, K I N D)=\operatorname{MO}(M, K I N D)+Z E R O$

is required to climinale the negative zeros and the following slatement

$I F(M O(M, K I N D)-H, T . O) M O(M, K I N D)=M O(M, K I N D)+1$

is required to adjust negalive numbers to their one's-eomplement form. On other installations, different methods may be required to account for rord size and form. Ihe problem of conversion could be avoided by using lwo machines with compatible floaling-point formals or using one machine lo do everything.

The only construetions that are not standard FORTRAN are an oceasional IH' ... 'THEA ... ELSE ... ENDIF, and the input and output in MAN, SETDAT, and IIR'PUIF. Unit 6 is used for oulput of the dala for the Varian; unit 12 is used for output of the debugging informalion, if requested; and unit 10 is used for the input file. Unit 59 is the lerminal used both for input of specificalions and outpul of messages.

The variable l'ls in main, eurrently set equal to 8 , may be changed to 9 to wille the output direclly to tape instead of, to disk. For this case, the prompl TAPE NAME replaees OU'PUT FILE NANE. When the name is supplied, the program halts until the lape is mounted. In this latter case, eonsistenl parity errors can be expecled and crror-recovery procedures should be added to the routine WRTBUF'.

The subroutine NlifFll, is called to open the output file and subsequently, urch lime a file is full, to open a new one. 


\section{REFERENCE}

I. K. linow!ton and 1.. Cherry. "ATOMS - A 'three-D Opaque Molecule Syslem - for Color Pictures of Space-liling or Ball-and-Slick Modules." Computers and Chemistry 1, 161 (1977).

$$
5
$$




\section{APPENDIX A. SAMPLE DATA AND INTERACTIONS}

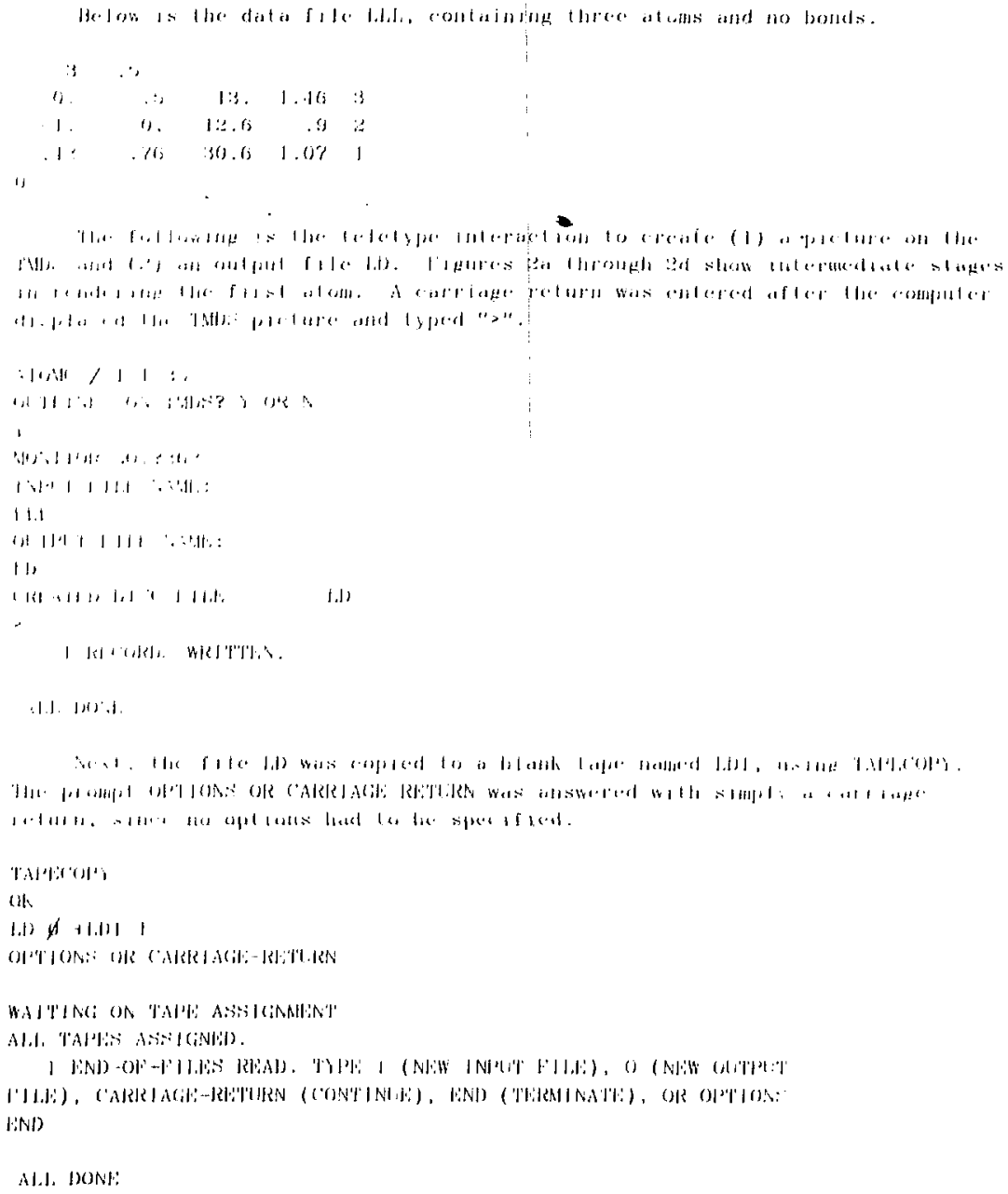


Bo low is lige completed Jicomed job request form, which should be attached to llac tape wheli a ls sibmit ted.

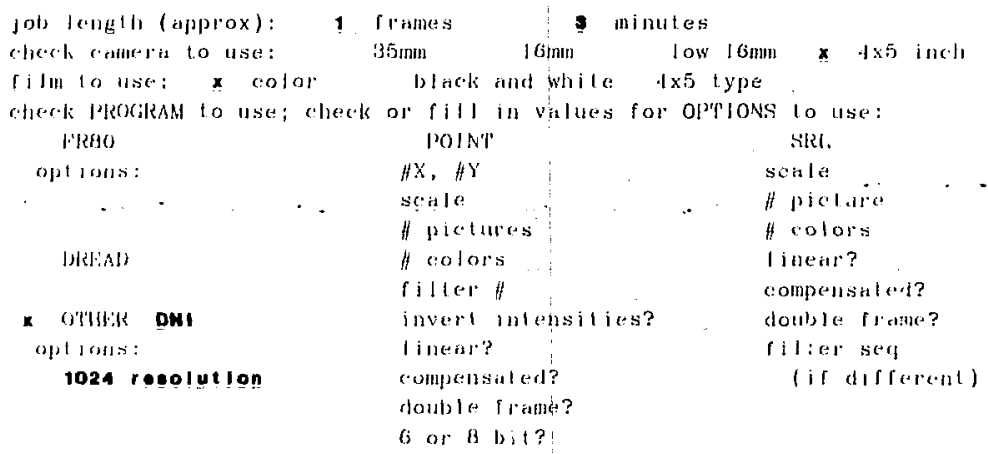

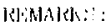

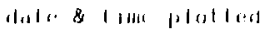

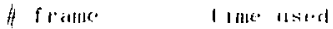

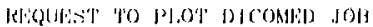

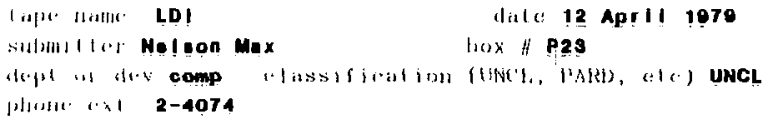

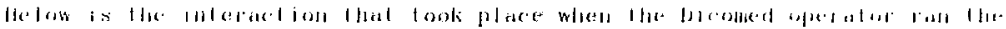

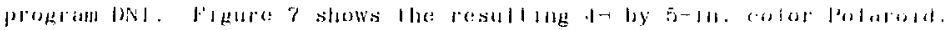

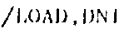

IWAI'I, IH'IS, :II

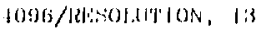

1

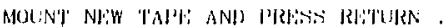

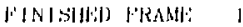

$\mathrm{d} * *$ 


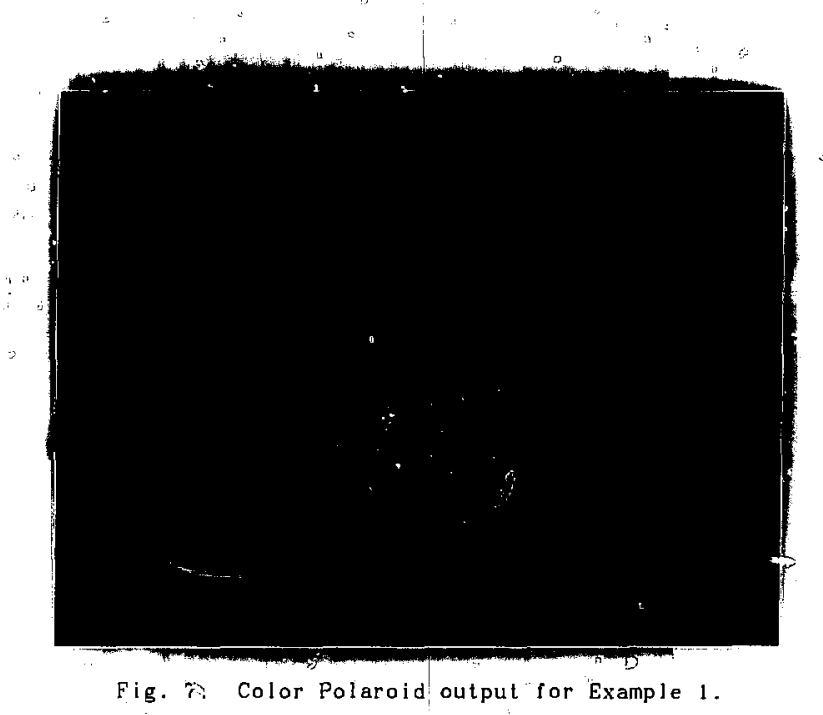

Next, we consider the Iile SDATA, which deseribes three different views of a Lhree-atom structure, including bonds. Here is the data file:

\begin{tabular}{|c|c|c|c|c|}
\hline 3 & .37 & & & \\
\hline-1 & -1 & 10. & .7 & 1 \\
\hline-1 & 2 & 12. & 1.2 & 2 \\
\hline 2. & $\begin{array}{r}-2 . \\
.2\end{array}$ & 14. & 1. & 3 \\
\hline 12 & & & & \\
\hline 13 & & & & \\
\hline 3 & .37 & & & \\
\hline-1 & -1 & 20 & .7 & 1 \\
\hline-1 & 2 & 24 & 1.2 & 2 \\
\hline 2. & $\begin{array}{r}-2 \\
.2\end{array}$ & 24 & 1. & 3 \\
\hline 12 & & & & \\
\hline 13 & & & & \\
\hline 3 & .37 & & & \\
\hline-1 & -1 & 20. & 1.4 & 1 \\
\hline-1 & 2 & 24. & 2.4 & 2 \\
\hline 2. & $\begin{array}{r}-2 \\
.2\end{array}$ & 24. & 1. & 3 \\
\hline 12 & & & & \\
\hline 13 & & & & \\
\hline
\end{tabular}


Agiin. the three Irames appeared on the TMDS. The output ille SD was copied to lape and run on the Dicomed.

ATOMC $/ 11.1$

OUTLINES ON TMDS? Y OR $N$

Y

MONITOR NO ? ?62

INPUT FILE NAME:

SDATA

OUTPUT FILE NAME:

SDA

CREATED DISC FILE SDA

$>$

$>$

$>$

1 RECORDS WRITTEN.

ALL DONE

TAPECOPY

OK

SDA $\varnothing+S D E 1$

OPTIONS OR CARRIAGE-RETURN

WAITING ON TAPE ASSIGNMENT

ALL TAPES ASSIGNED.

1 END-OF-FILES READ. TYPE I (NEW INPUT FILE), O (NEW OUTPUT FILE), CARRIAGE-RETURN (CONTINUE), END (TERMINATE), OR OPTIONS END

\section{ALL DONE}

The TMDS pictures are in Fig. 8 and the first two colar output pictures are shown in Fig. 9. Note that the pictures have been clipped at the frame boundaries. Figure 10 shows six base pairs of DNA, including approximately 400 atoms. It look 2 seconds on the CDC 7600 for ATOMLLL ta complite the visible parts of this structure, and 100 seconds for the picture to be shaded by DN! and platted on the Dicamed. 


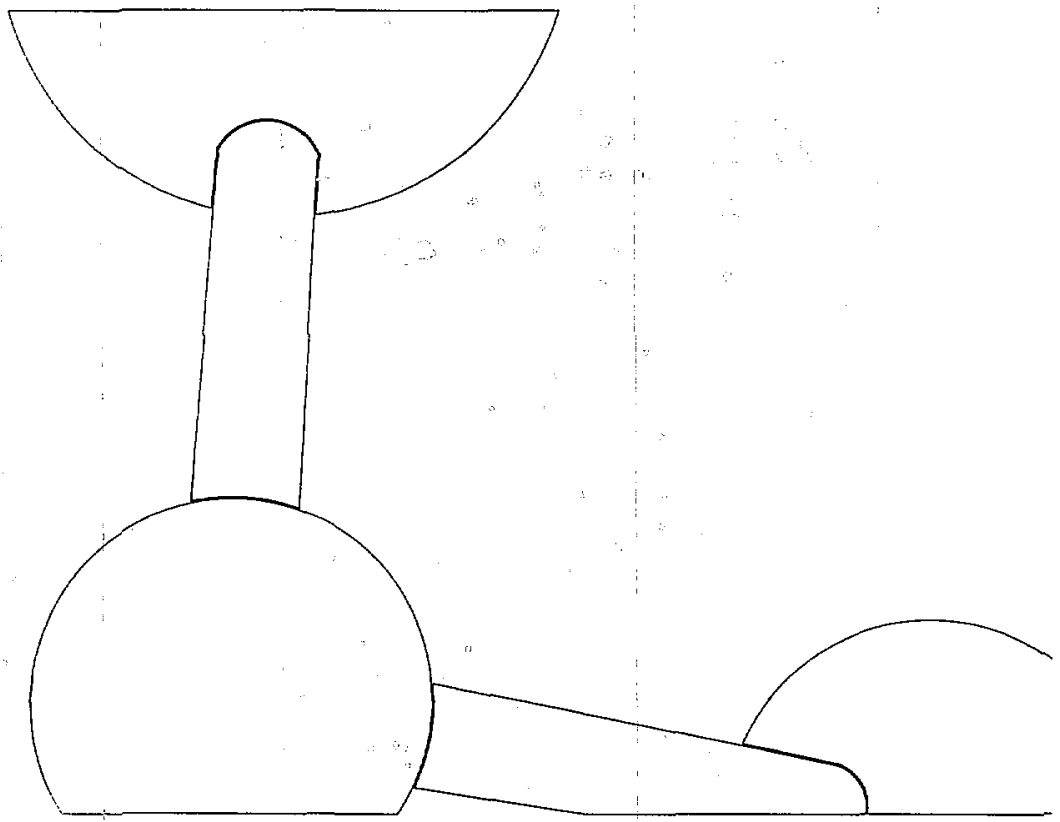

$\because$

$\therefore$

Fig. 8.(a) Line-drawing output for Example 2, first frame, showing closeup. The lelevision monitor display system (5l2- by 512-pixels resolution) has been rescanned at higher resolution for this report. 


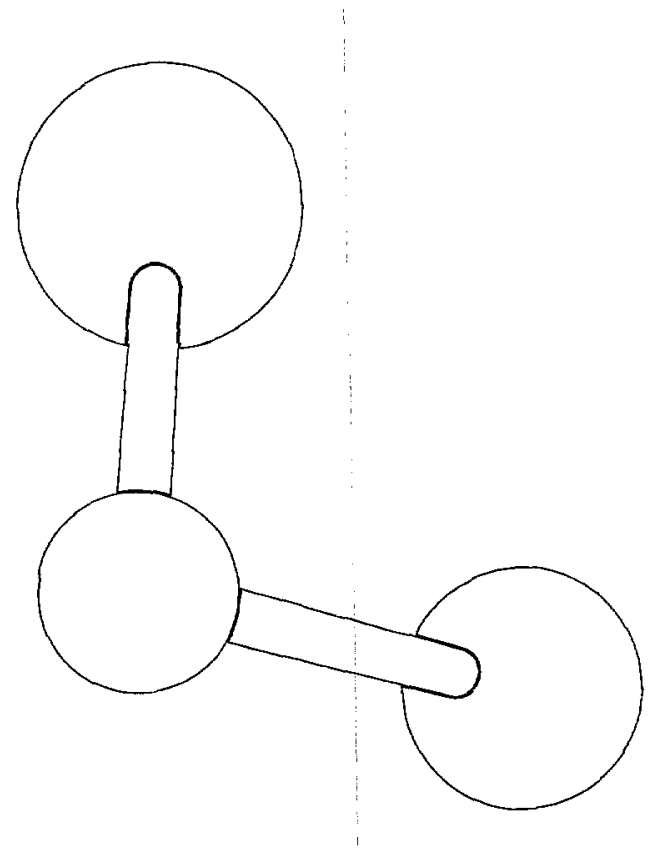

Fig. 8.(b) Line-drawing output for Example 2 , second frame. The molecule has been moved $f$ arther away. 


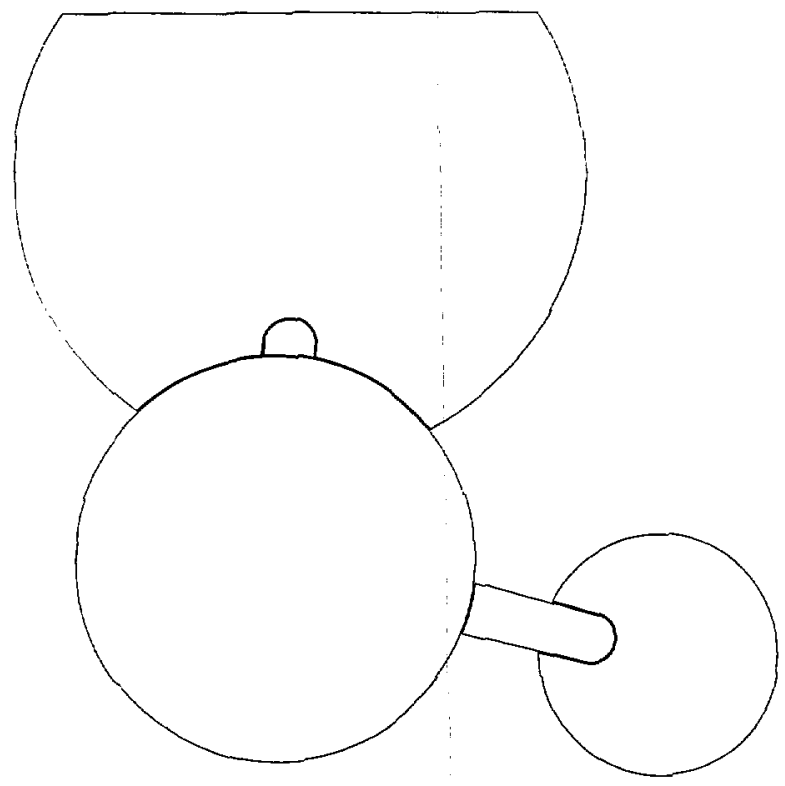

Fig. 8.(c) Line-drawing oulput for Example 2, third frame. The alom radi i have been increased. 


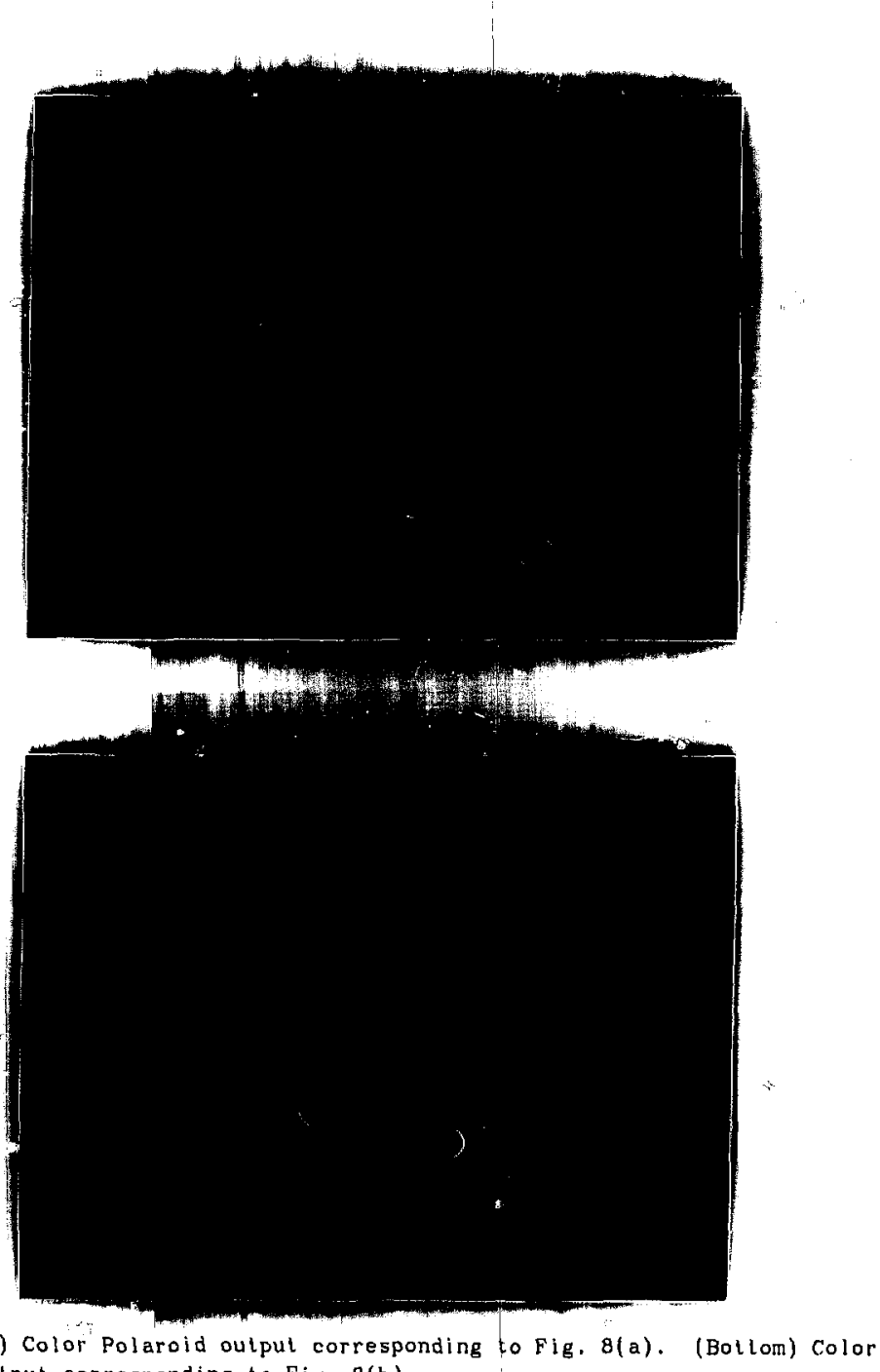

Fig. $\theta$ (1op) Color Polaroid output corresponding to Fig. 8(a). (Botlom) Color Polaroid output corresponding to Fig. $\theta(\mathrm{b})$. 


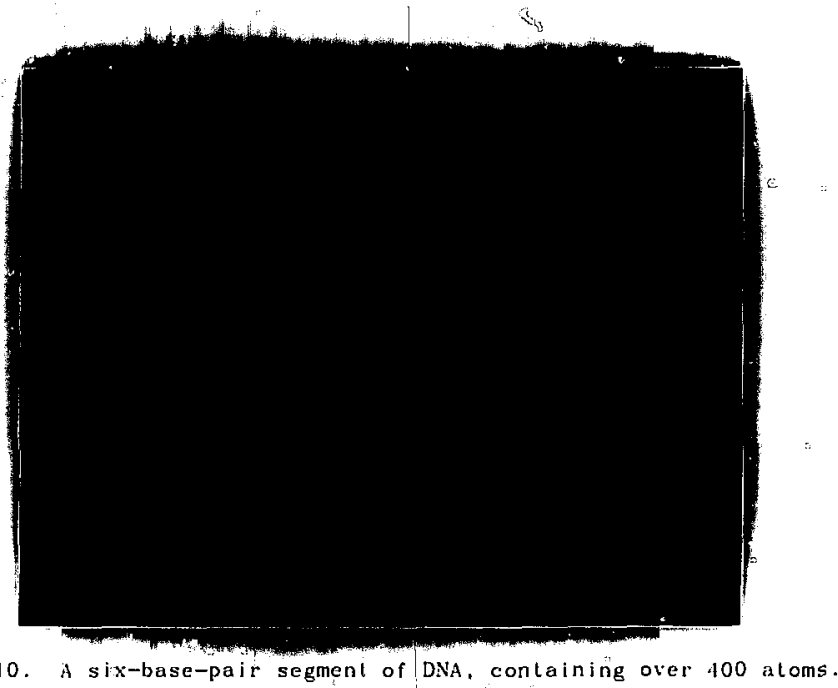




\section{APPENDIX B. ERROR MESSAGES}

The following error conditious are reported on the user's torminal. If

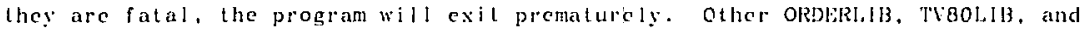
system error messages may also occur.

$n$ BAD TRAP PASSED

Subroutine ALIST has becn asked to add to part n's list of visible traperoids a trapczoid for which XTL \& YBL, YTR \& YBR, or Xik \& Xl. This traperoid will not be added and a black gap may appear in the pielure. This could be caused by a round-of error or, more likely, a bug in the program logic. The error is not your faull, and there is nothing you can do except complain to the authoi.

BAD 'TRAP (TREATED BY BRAKLP

This message will appear, with circumstances and consequences similar to the one above, when BRAkLP creales a bad trapezoid by subdividing a convex region. It could be caused by a bug in BRAkLP or by incorrect input to BRAktP. Again, there is nothing you can do aboul this.

NORE: THAN 7 TRAP FOR MASK

Only scven spaces are allowed in the common arrays in /TRAPP/ for mask trape\%oids. This message indicales that BRAKUP has found more than this. probably due to an incorrect counterclockwise lour of the boundary of the projection of a bond. Again, nothing can be done. 'lhe abov threc crrors will cause a (hoperully small) trapezoid to be left out and should not seriously af rect the final pieture.

NELSON CANNOT' CRE: T'E <name>

Fatal

The system was unable to create the oulpul dala file enames requcstcd by NEHFlL, probably because not enough disk space or file index space was availablc. Rerun the program afler files have been released by you and olher users.

ERROR WRI'TING OU'TPUT' F I LE.

Fata!

Subroutine WRTBUF found an error condition after writing the oulput buffer. This is unlikely for a disk file, but parity errors may be expected consistently if ITM was changed to $\theta$ so that the output goes directly lo tape. Error recovery procedures should be added to WRTBLF.

BOND LOST' FROM BAD 'TRUNCATION $n$

Subroutine CTRAP tried to shrink by DELTAR the region that it created for a bond. It found that an end arc did not intersect the bond profile line at. corner $n$. The bond will be missing from the picture. This would be due to a software bug, and there is nothing a user can do but report it. 
(l'rom subroutine dDDs.) The linked lists of inlepactions in IWHERE and NFST are not large enough. Increases the ir size as suggesled in section 5 .

TOO MANY BOLXDARY ARCS

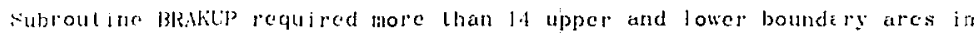
teriporary storage when breaking up a convex region into trape\%oids. This is probably duc 10 a bad specification of the boundary in its input. Again, a sof ware bue lhat is not the user's faull. 


\section{APPENDIX C. SUBROUTINES}

\begin{tabular}{|c|c|}
\hline MiN & assigns input and output files: \\
\hline SE'T'DAT' & reads input dala \\
\hline PICTLR & loops by color \\
\hline $1 \times 1 \mathrm{~L}$ & calculates picture plane coordinales \\
\hline $\operatorname{kschx}$ & lists possible interactions \\
\hline $\mathrm{IBOA}$ & bond-alom interaction \\
\hline IBB & bond-bond interaction \\
\hline IAA & alom-atom interaction \\
\hline DIGES'T & processes list of interactions: \\
\hline$C I R C I R$ & finds inlerscetion of two circular ares \\
\hline $\mathrm{K} I \mathrm{ND}$ & kind of arc \\
\hline POIN"I' & calculates y-coordinale of are \\
\hline SLOPE: & calculates slope of are \\
\hline ERASE & makes part invisible \\
\hline $1 B O X$ & preliminary bond-atom overlap \\
\hline ICCPAR & compares two circles \\
\hline DIST & square of distance from origin \\
\hline BLOCK DA' & \\
\hline FREE & returns an interaction list to free storage \\
\hline ALIST & adds trapezoid to list for part \\
\hline CINT & intersection of two arcs \\
\hline CIRLIN & intersection of circular are and line \\
\hline TRUNC & 3-space intersection of two spheres \\
\hline ADDA & adds lo inleraction $l$ ist \\
\hline 'T'I'RUNC & makes mask trapezoids for truncalion \\
\hline BRAKLP & turns convex region into lrapezoids \\
\hline TRAP & compares mask and part lrapezoids \\
\hline A'TRAP & does non-lrivial trapezoid inleractions \\
\hline C'I'RAP & creales trapezoids for part or mask \\
\hline ou'lPu'l' & formats trapezoid list for oulpul \\
\hline COMPAC'T' & rejoins adjacent trapezoids \\
\hline WR'TBUF & adds a row to outpul array \\
\hline NEWF IL & ereates a new disk file \\
\hline
\end{tabular}




\section{APPENDIX D. VARIABLES AND ARRAYS IN COMMON}

COMMON/MCONST/NCOL, NATOMS, NBONDS, CAMX, CMIY, CAM?, MIMK, AIMY, ALMZ, ZMIX, PRATIO, ARATIO, DELIAR, NTRPPP, VIMX, VIMY, VIMZ, IFIRST, NTOPRP, ITV, IHV, FINISHED

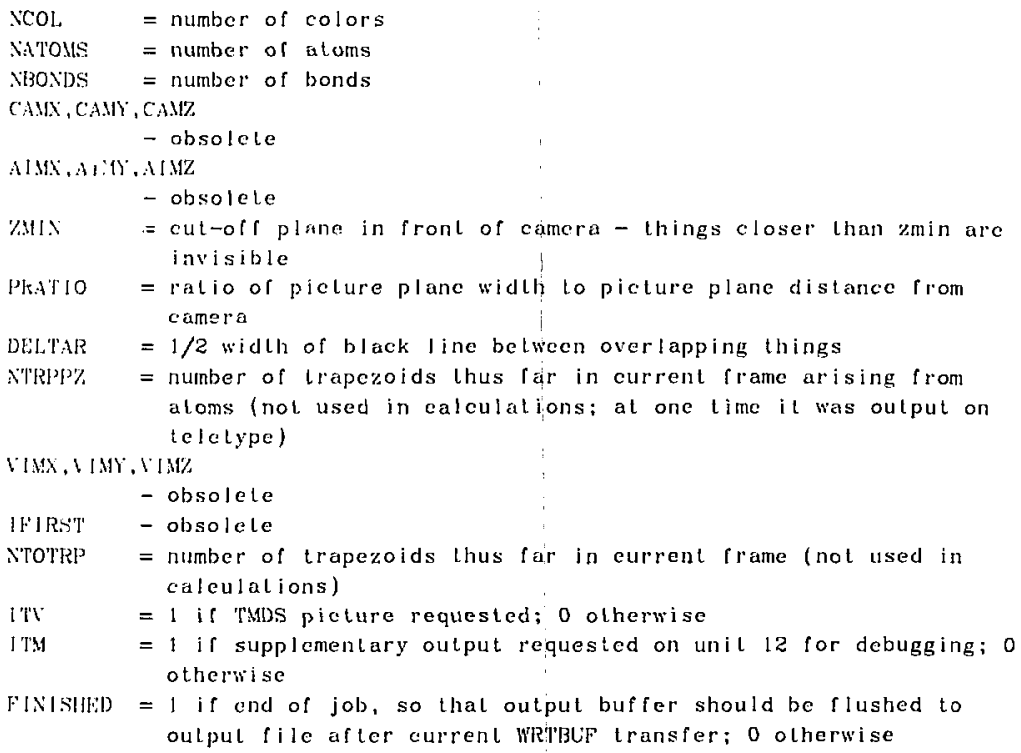

COMMON/MINH/AMIIN

WMIN = minimun width of trapezoid

COMMON /TOUT/NOU', KLQU(600), I.O(11), KO(11), TAPENAME, RECORDS

KEQU is equivalenced to the byte(18) array KOUT(200,11); LO and KO are equivalenced to the array $\operatorname{MO}(11,2)$

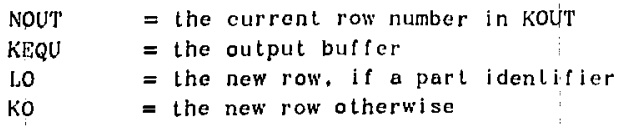


TAPENAL: = name (or bin number) of current output tape

XIRECORDS = number of records on current oulput file

ISCNAME = name of current disk outpul file.

ITM $=8$ for disk output or 9 for tape outpul

COMMON /COM/ZPICT, NSUM, NBS

ZPlCl $\quad=$ distance of 2-wide picture plane from camera, = 2/PRATIO

NSLM = tolal mumber of things (NAl'ONS+NBONI)S)

NBS $\quad=$ where bonds starl (NATOMS+1)

COMNON $/ \mathrm{MCORD} / \mathrm{COORD} /(0605,8)$

Contains atoms and bond coordinates. Coord is alway equivalenced to arrays CIR, ATONS, BONDS, and always indexed as in column 3 below to improve

clarity of code

atoms :

$\operatorname{coORD}(*, 1)=\operatorname{ATOMS}(*, 1)=\operatorname{ATOMS}(*, 118)=3 \mathrm{~d}$ radius

$\operatorname{COORI}(*, 2)=\operatorname{ATOMS}(*, 2)=\operatorname{ATOMS}(*, I X)=3 \mathrm{~d}$ X center

$\operatorname{COORD}(*, 3)=\operatorname{ATOMS}(*, 3)=\operatorname{AtOMS}(*, 1 Y)=3 \mathrm{~d} Y$ cenler

$\operatorname{COORD}(*, 4)=\operatorname{ATOMS}(*, 4)=\operatorname{ATOMS}(*, 1 Z)=3 \mathrm{~d} z$ center

$\operatorname{COORD}(*, 5)=\operatorname{ClR}(*, 5)=\operatorname{ClR}(*, \mathrm{CR})=\mathrm{pp}$ radius

$\operatorname{COORD}(*, 6)=\operatorname{CIR}(*, 6)=\operatorname{CIR}(*, \mathrm{CX})=\mathrm{pP} X$ center

$\operatorname{COORI}(*, 7)=\operatorname{ClR}(*, 7)=\operatorname{CIR}(*, \operatorname{CY})=$ pp Y center

$\operatorname{COORD}(*, 8)$ unused

bonds:

$\operatorname{COORI}(*, 1)=\operatorname{BONDS}(*, 1)=\operatorname{BONDS}(*, N R)=$ ncar-end pp radius

$\operatorname{COORD}(*, 2)=\operatorname{BONDS}(*, 2)=\operatorname{BONDS}(*, N X)=$ near-end pp $X$

$\operatorname{COORD}(*, 3)=\operatorname{BONDS}(*, 3)=\operatorname{BONDS}(*, N Y)=$ ncar-end pp $Y$

$\operatorname{COORD}(*, 4)=\operatorname{BONDS}(*, 4)=\operatorname{BONDS}(*, N Z)=$ near-end $3 d \mathrm{Z}$

$\operatorname{COORI}(*, 5)=\operatorname{BONDS}(*, 5)=\operatorname{BONUS}(*, F R)=$ far-end pp radius

$\operatorname{COORD}(*, 6)=\operatorname{BONDS}(*, 6)=\operatorname{BONDS}(*, F X)=$ rarmend pp $X$

$\operatorname{COOIRD}(*, 7)=\operatorname{BONDS}(*, 7)=\operatorname{BONDS}(*, F Y)=\{$ ar-cend $\mathrm{pp} Y$

$\operatorname{COORD}(*, 8)=\operatorname{BONDS}(*, B)=\operatorname{BONDS}(*, F X)=$ far-eind $3 \mathrm{~d} \%$

COMMON /MCONS'I/IR, IX,IY,IZ,CR, CX,CY,IAI, IAZ,NR, NX,NY,NZ, FR, FX, FY, FZ

constants for indexing into coord and its equivalenccil arrays as deseribed above

COMMON/MCOL/ICOL $(0605,3)$

ICOL is equivalenced lo $N A C$ and MBONDS

atoms :

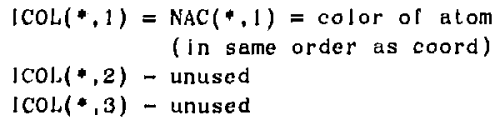


bonds:

1 col. $(*, 1)=$ color of bond

$1 \mathrm{COI}_{+}(*, 2)=$ MBONDS $(*, 1)=$ new index of near end a lom

I $\operatorname{COL}(*, 3)=\operatorname{MBO}(1) \mathrm{s}(*, 2)=$ new index of far end atom

COMNON /1.1/1471R:RE: $(4700)$

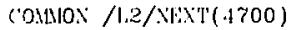

COMNON $/ 1,3 / 1,4$ ST $(0605)$, LPPTR

linked list of possible interactions

LAST(*) is indexed by alom-bond number and points to the last enlry for that atom or bond or 0 if none

NEXT(*) points to the next enlry - indexed by number obtained from LAST or NEST

MHLIRE(*) contains the number of the atom or bond to interact, negative number if truncalion or 0 for piclure plane mask

LiPTR is next empty place in NEXT and IHHERE

CONAON /TRNPP/IPTRM(7) , IP'TRP( 50$), \operatorname{KTBM}(7), \operatorname{KTBP}(50), \operatorname{KBBM}(7), \operatorname{KBBP}(50)$,

$R^{\prime} I^{\prime} N(7), R^{\prime} I^{3}(50), \operatorname{RBM}(7), \operatorname{RBP}(50), X C C^{\prime} M(7), \operatorname{XCTP}(50)$,

$X C B M(7), X C B P(50), Y C T M(7), Y C T P(50), Y C B M(7), Y C B P(50)$,

Y'ILA( 7), YTLP( 50$), Y B L M(7), Y B L P(50), Y T R M(7), Y ' T R P(50)$.

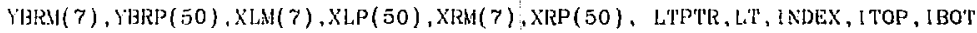

'TR:Pl' contains the parameters that deseribe the trapezoi is. In most

roulines $i l$ appears as above where names ending in " $m$ " describe masks and wher names ending with "p" deseribe parts. In subroutine BRAKuP, the mask and parl names are pul together inlo 1 array, so IPTRM(7). IPTRP(50) becomes JP'R (57), elc, in roulines POINT, SLOPL, ALIST, CINT the top and bottom arrays are also combined so RTM, RTP. RBM, RBP are combined into R(114).

IPf'R! = contains the index of the next mask trapezoid or 0 for last

IP'leP = contains the index of the next part trapezoid or 0 for last

KTHW, KTBP, KBBBN, KBBP

- kind of top(KIP) or boltom (KBB) boundary - 1=convex up, $2=$ concave up, $3=1$ ine

RT'M, R'T', RIBM! , IIBP

- radius of top(R'l) or botlom(RB) arc if boundary curved, or slope

XC'M, XCTP, XCl3M, XCl3! if boundaly is a line

- X-coordinatc of center of top(XCT) or bottom(XCB) are if YCTM, YCTP, YCEM, YCBP boundary is curved; or Y-intercepl if boundary is a line

- Y-coordinate of center of top(YCT) or bot Lom(YCB) aro if boundary is curved; unused if boundary is a line

YTLM,YTLP, YBLM, YBLP

- Y-coordinale of lop left(YTL) or bottom left(YBL) corner of irapezoid

YTRM, YTRP, YBRN, YBRP

- Y-coordinale of top $r i g h t(Y T R)$ or bollom $r i g h L(Y B R)$ corner of 


\section{traperoid}

$\therefore L, M, X I, P, X R M, . X R P$

- X-coordinate of $10 I\left(\left(X_{1}\right)\right.$ and right(X) edge of trapezoid

l.TP'l'? - next emply place in arrays

LiT - index of trapezoid pointing to I (for linking in alist)

INDEX - index of boundary for point of slope

I'lol' - index of lop boundary for new tiap passed lo ALIS'

IBO'T - index of botlom boundary for new trap passed to Mlas'

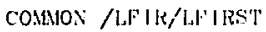

LFIRST is index of first part trapezoid or 0 if none

COMMON /ATRAPP/AR, I'TL, YBL, TYT'L, TYBL, NR, Y'TR, YBR, TY'I'R, TYBR

contains the corner coordinales of the mask- and part-overlap regions found by digest and passed to TRAP

$X R, X L=I 0 f L$ and $F i g h t X$-coordinales

YTL, YHL, Y'T'R, YBHR

$=$ top and boltom left and top and bollom right Y-coordinales for part

'I'Y'T'L, I'T'HI, ,TY'T'R, 'I'YBR

$=$ lop and bollom lefl and lop and boltom righl l-coordinales for mask

COMNON /IXTERC/IFI,QB, XLBB, XLBB, XRBB, Y'RBB, IFLG' , XLTB, YL'TB, XR'TB, YRT' I , K, I 7, I7B, KB used primarily to pass parameters from I'RAP to ATRAP

IFLGl] = number of intersections between either top of part and top of mask or boltom of part and boltom of mask or 3 if none (XLBB, YLBB), (XRBB, YRBB) are the intersections

1FLGT = number of intersections between either the top of part and botlom of masl or bottom of part and top of mask, or 3 if none (XL'TB, YL'TB), (XR'I'B, YR'T'B) are the intersections

$1=$ index of part trapezoid

$K=$ index of mask trapezoid

$17=$ index of part if mask and part arlays combined

$17 \mathrm{~B}=$ index of bottom of part if mask and part arrays combined and top and bottom arrays combined

KB = index of bottom of mask if mask und part arrays combined and top and bottom arrays combined

COMMON /lOOPS/INARC(14),XC(14), YC(14), RA(14),XI(14), YI(14),

IFIG, IPREV

defines boundaries of enclosed area for brakup

INARC = index of next are or line (clockwise) 
XC.YC = center or arc or slope and 8 -intercepl of line

R.A = radius of arc or 0 for line

$x l, j l=$ end point of arc or line

IFLG = index of starling lraperoid (i.e. $1=$ mask, 8=part)

IPREY = number of ares and lines

COMNON/JBALL,/J

\rfloor$=$ parl number of eurrent part

CONAON /ETIRL XK/XTRUNK, YTRLNK, RTIRLNK

used to slore definition of concave truncation are on the end or a bond, caused by intersection with near atom!

X'TRL'NK, Y'TRLWKK

$=X-$ and $Y$-coordinates of the center of arc

RTRL:Sk = the radius of are

COMBON /I'EMPL,

used lo store some lemporary variables in subroutines; vestige of a minicomputer implementation with space limitations 